\title{
Quality Evaluation of Shallow Groundwater in Luoyang City Based on Fuzzy Mathematics
}

\author{
Ding Jihui ${ }^{1}$, Xiang Mengjia ${ }^{1}$ Lixiang $^{2 *}$, Yang Jingjing ${ }^{2}$, Zhu Jianchao ${ }^{2}$ \\ ${ }^{1}$ College of Civil Engineering and Architecture, Hebei University, Baoding, 071002, China \\ ${ }^{2}$ A State Key Laboratory of Environmental Criteria and Risk Assessment, Chinese Research Academy of \\ Environment Sciences, Beijing 100012, China \\ Email: lixiang@craes.org.cn
}

\begin{abstract}
Based on the investigation of shallow groundwater environment in Luoyang City, thirty two groups of groundwater samples were collected and conducted relevant water quality analysis, sixteen of which were selected as the evaluation indexes. A comprehensive evaluation of Luoyang groundwater was conducted by resorting to fuzzy mathematics. It is concluded that water sample I, sample II, sample III, sample IV, sample V accounted for $6.25 \%, 37.5 \%, 37.5 \%, 6.25,12.5 \%$ of the total. The groundwater quality was largely at a moderate state. In conclusion, comparative analysis by resorting to comprehensive index method, fuzzy comprehensive method using membership degree to evaluate groundwater quality, and it proved fuzzy mathematics more comprehensive and reasonable. Groundwater pollution is mainly concentrated in industrial parks and densely populated urban areas. Such parameters as total hardness and nitrogen were the main causes of groundwater contamination in the study area.
\end{abstract}

Keywords: Luoyang city; groundwater quality; fuzzy mathematics; comprehensive index method

\section{Introduction}

Luoyang City is located in the west of Henan Province, the western end of the Luoyan basin, the eastern part of the Eurasian Continental Bridge, across the middle reaches of the Yellow River, geographical coordinates: latitude $33^{\circ} 35^{\prime} \sim 35^{\circ} 05^{\prime}$, longitude $111^{\circ} 08^{\prime} \sim 112^{\circ} 59^{\prime}[1]$. Luoyang City, as the focus of the construction of the central and western cities, the scale of the city has been expanding in recent years, and the population continues to increase, industrial and agricultural pollution is also more and more serious. Groundwater is the main drinking water source of the city in Luoyang, which accounts for 90 percent of the city's total water supply. The excessive exploitation of groundwater in Luoyang and the irrational discharge of waste water caused by industrial and agricultural production have been increasing. The content of certain chemical components in groundwater has been increasing continuously, which has a significant impact on the regional groundwater environment[2-4]. Therefore, it is necessary to carry out the analysis of groundwater quality and water quality evaluation in Luoyang city area, and to further explore its causes and highlight the corresponding prevention and control measures according to the geological and hydrological conditions and the characteristics of pollution sources in the study area.

At present, there are many researches about groundwater quality evaluation at home and abroad, including single factor pollution index[5], comprehensive pollution index method[6], fuzzy comprehensive evaluation method[7-9], artificial neural network method[10], etc.. Fuzzy comprehensive evaluation overcomes the shortcomings of other methods considering the ambiguity of nature, with membership to represent the influence degree of each index measured concentration on water quality, has certain scientific and rational, also accord with the actual status of pollution[11]. A comprehensive evaluation of Luoyang groundwater was conducted by resorting to fuzzy mathematics. It has high theoretical value and practical guiding significance for scientific and rational utilization of Luoyang groundwater resources.

\section{The Brief Introduction of Research Area}

Luoyang city for many years, the average total water resources 2 billion 809 million $\mathrm{m}^{3}$, the per capita share of less than $450 \mathrm{~m}^{3}$, with the province's per capita share of basic flat, about $1 / 5$ of the country's per capita 
share, is a serious shortage of water in the North City[12]. The annual average precipitation 625mm, day maximum precipitation is $134.9 \mathrm{~mm}$ ( $\mathrm{p}=50$ year), maximum annual precipitation is $1063.2 \mathrm{~mm}$, the minimum annual rainfall $337.9 \mathrm{~mm}$. Precipitation is concentrated in June, July, August and September. The average annual evaporation is $1829.1 \mathrm{~mm}$. The main water system in the study area is the porous water system of loose rock, which is mainly distributed in the plain area of Luoyang, City, mainly in the Quaternary Cenozoic sediments, and the landform type is Yiluo River alluvial plain. Shallow groundwater system receives atmospheric precipitation, surface water, irrigation back to the water. Groundwater excretion through artificial mining, diving, lateral runoff, etc, horizontal runoff is weak [13]. In the multi-year average groundwater level with the following, the total storage of water amounted to 1.171 billion $\mathrm{m}^{3}$, the annual comprehensive supply volume reached 252.4 million $\mathrm{m}^{3}$, of which from the Luo River, Jian River, Yi River and other surface water supply of 156.1 million $\mathrm{m}^{3}$, accounting for $62 \%$ of total groundwater recharge. Especially the Luo River supply of 114 million $\mathrm{m}^{3}$, accounting for $45 \%$ of total groundwater recharge [14].

\section{The Sources of Data}

The groundwater monitoring data of 32 wells were selected in Luoyang city in 2012. Distribution of groundwater monitoring well in the study area is shown as figure 1.The main quality components including $\mathrm{pH}, \mathrm{Al}, \mathrm{Fe}, \mathrm{Mn}, \mathrm{Cu}, \mathrm{Zn}$, Chloride, Sulfate, Total dissolved solids, Total hardness, Oxygen consumption, Volatile phenols (Phenol), Ar, Cd, $\mathrm{Cr}^{6+}, \mathrm{Hg}$, Se, Fluoride, Cyanide and Nitrate (N), a total of 21 water quality data statistics is shown as table 1.

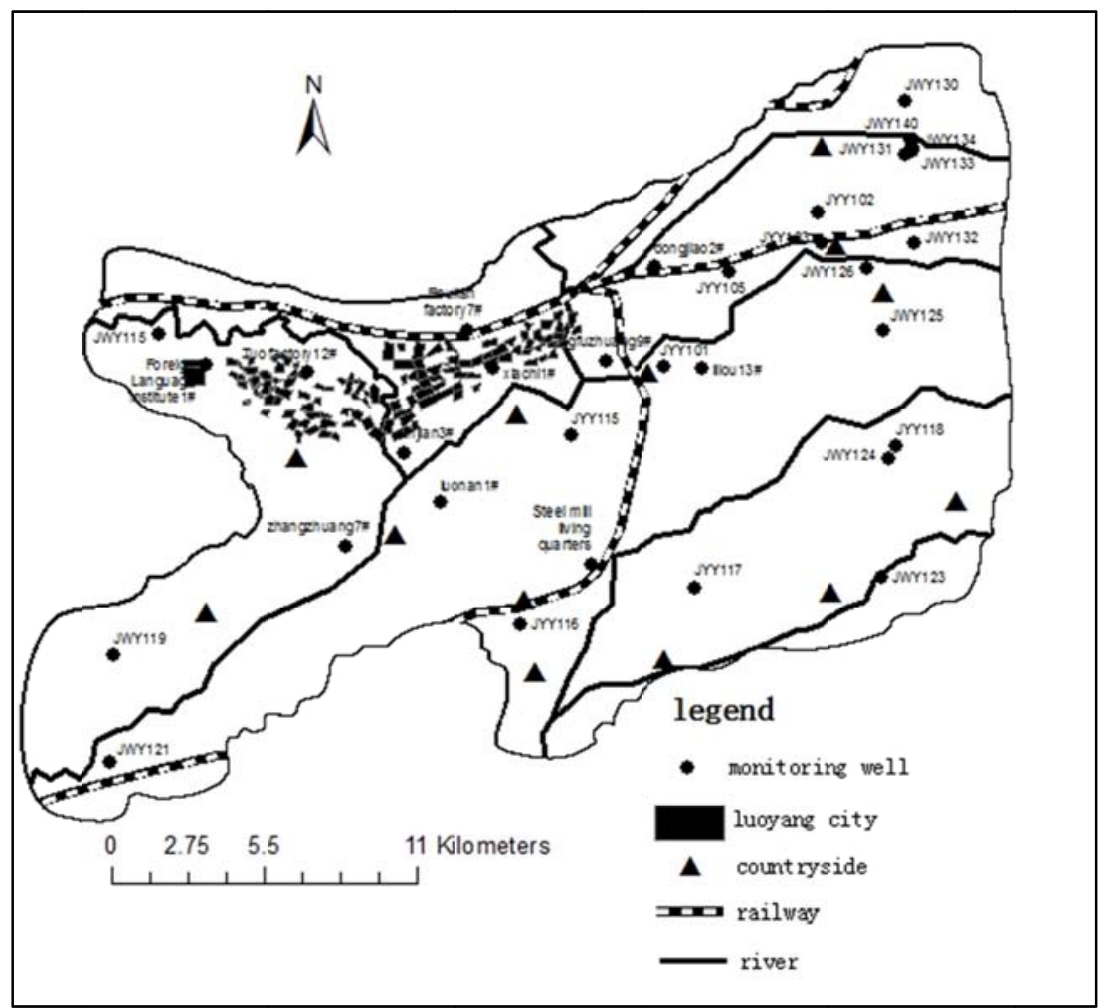

Figure 1. Distribution of groundwater monitoring well in the study area

Table 1. Statistics of main indicators' content features of groundwater quality in the study area

\begin{tabular}{l|l|l|l|l|l}
\hline name & average value & $\max$ & $\min$ & variance & Skewness \\
\hline $\mathrm{pH}$ & 7.68125 & 6.97 & 8.63 & 0.416224 & -0.07243 \\
\hline $\mathrm{Al}$ & 0 & 0 & 0 & 0 & 0 \\
\hline
\end{tabular}




\begin{tabular}{l|l|l|l|l|l}
\hline $\mathrm{Fe}$ & 0.0590625 & 0 & 0.35 & 0.075181 & 1.954998 \\
\hline $\mathrm{Mn}$ & 0.0009375 & 0 & 0.01 & 0.002915 & 2.926498 \\
\hline $\mathrm{Cu}$ & 0 & 0 & 0 & 0 & 0 \\
\hline $\mathrm{Zn}$ & 0.0075 & 0 & 0.08 & 0.016583 & 3.269787 \\
\hline Chloride & 65.1453125 & 9.08 & 323.16 & 57.4284 & 2.971266 \\
\hline Sulfate & 100.5184375 & 17.05 & 276.41 & 47.11266 & 1.53416 \\
\hline Total dissolved solids & 640.684375 & 239 & 1779.9 & 263.6166 & 2.525931 \\
\hline Total hardness $\left(\mathrm{CaCO}_{3}\right)$ & 431.2134375 & 179.94 & 1011.51 & 154.9845 & 1.461533 \\
\hline Oxygen consumption & 0.8440625 & 0.27 & 3.36 & 0.689592 & 3.146694 \\
\hline Volatile phenols & 0 & 0 & 0 & 0 & 0 \\
\hline Ar & 0.00003125 & 0 & 0.001 & 0.000174 & 5.656854 \\
\hline $\mathrm{Cd}$ & 0 & 0 & 0 & 0 & 0 \\
\hline $\mathrm{Cr}{ }^{6+}$ & 0.0054375 & 0 & 0.031 & 0.009107 & 1.810233 \\
\hline $\mathrm{Pb}$ & 0.000115625 & 0 & 0.0037 & 0.000644 & 5.656854 \\
\hline $\mathrm{Hg}$ & 0.0000875 & 0 & 0.0015 & 0.00034 & 3.830122 \\
\hline $\mathrm{Se}$ & 0.000690625 & 0 & 0.0055 & 0.001147 & 2.669964 \\
\hline $\mathrm{Cyanide}$ & 0.00075 & 0 & 0.002 & 0.000968 & 0.542149 \\
\hline $\mathrm{Fluoride}$ & 0.3921875 & 0.18 & 0.83 & 0.134088 & 0.993362 \\
\hline $\mathrm{Nitrate}(\mathrm{N})$ & 19.211875 & 1.03 & 164.91 & 27.31999 & 4.928819 \\
\hline
\end{tabular}

unit: $\mathrm{mg} / \mathrm{L}$

\section{Fuzzy Comprehensive Evaluation of Plain Groundwater in Luoyang Based on Fuzzy Mathematics}

\subsection{Brief Introduction of Fuzzy Comprehensive Evaluation Method}

Due to complex hydro-geological systems and inherent uncertainties in measurement and analysis, water pollution is a fuzzy concept. Fuzzy comprehensive evaluation is a very effective multi-factor decision-making method for making a comprehensive evaluation of things affected by various factors. It is characterized by a fuzzy set to represent the evaluation results rather than absolutely positive or negative. The introduction of fuzzy mathematics into groundwater quality assessment can better reflect the uncertainty and fuzziness[15]. The fuzzy mathematics comprehensive evaluation method mainly includes several parts:

1. Determination of Membership Function Y

The membership degree can be expressed by the membership function. The linear membership function is used to determine the degree of membership of each rating factor: $\mathrm{j}=1$,

$$
y= \begin{cases}1 & X_{i} \leq S_{i, j} \\ \frac{S_{i, j+1}-X_{i}}{S_{i, j+1}-S_{i}} & S_{i, j}<X_{i}<S_{i, j+1} \\ 0 & X_{i}>S_{i, j+1}\end{cases}
$$

$\mathrm{j}=2,3,4$,

$$
y=\left\{\begin{array}{lc}
0 & X_{i}<S_{i, j-1} \\
\frac{S_{i, j+1}-X_{i}}{S_{i, j+1}-S_{i, j}} & S_{i, j} \leq X_{i}<S_{i, j+1} \\
\frac{X_{i}-S_{i, j-1}}{S_{i, j}-S_{i, j-1}} & S_{i, j-1} \leq X_{i}<S_{i, j} \\
0 & X_{i}<S_{i, j+1}
\end{array}\right.
$$

$\mathrm{j}=5$, 


$$
y= \begin{cases}0 & X_{i}<S_{i, j-1} \\ \frac{X_{i}-S_{i, j-1}}{S_{i, j}-S_{i, j-1}} & S_{i, j-1}<X_{i}<S_{i, j} \\ 1 & X_{i} \geq S_{i, j}\end{cases}
$$

where, $\mathrm{Y}$ is the factor belonging to each level of water membership;

$\mathrm{X}$ is measured concentration of each factor;

$\mathrm{S}_{\mathrm{i}, \mathrm{j}}, \mathrm{S}_{\mathrm{i}, \mathrm{j}+1}, \mathrm{~S}_{\mathrm{i}, \mathrm{j}-1}$ are the various levels of water quality standards.

2. Establishment of Fuzzy Relation Matrix R

The fuzzy relation matrix $R$ reflects the membership of the $j$-th water quality category corresponding to the $\mathrm{i}$-th water quality index, the formula is:

3. Weight and Normalization

$$
R=r_{i j}=\left[\begin{array}{cccc}
r_{11} & r_{12} & \cdots & r_{1 n} \\
r_{21} & r_{22} & \cdots & r_{2 n} \\
\cdots & \cdots & \cdots & \cdots \\
r_{m 1} & r_{m 2} & \cdots & r_{m n}
\end{array}\right]
$$

According to the parameters exceeding the standard weight, the more the standard, the greater the weight.

$$
\text { Weight value is; } \mathrm{W}_{i}=\frac{C_{i}}{S_{i}}
$$

where, Wi is the index of excess of the average pollutant content of i pollutants;

$\mathrm{Ci}$ is measured concentrations of i pollutants;

$\mathrm{Si}$ is the arithmetic mean of all kinds of standard values of $\mathrm{i}$ pollutants.

In order to perform the fuzzy operation, each individual weight is normalized:

$$
\mathrm{V}_{i}=\frac{W_{i}}{\sum_{i=1}^{n} W_{i}}=\frac{C_{i} / S_{i}}{\sum_{i=1}^{n} C_{i} / S_{i}}
$$

where, Vi is normalized weight of i pollutant;

$\mathrm{Ci}$ is ditto;

$\mathrm{Si}$ is ditto.

Thus the weight set is $A=\left(\begin{array}{llll}V_{1} & V_{2} & \cdots & V_{i}\end{array}\right)$

4. Fuzzy Matrix Compound Operation

The weight $\mathrm{A}$ and the fuzzy evaluation matrix $\mathrm{R}$ are combined to obtain the parameter evaluation matrix B of the evaluated water quality, such as the formula:

$$
B=A \cdot R=\left(\begin{array}{llll}
V_{1} & V_{2} & \cdots & V_{i}
\end{array}\right)\left[\begin{array}{cccc}
r_{11} & r_{12} & \cdots & r_{1 n} \\
r_{21} & r_{22} & \cdots & r_{2 n} \\
\cdots & \cdots & \cdots & \cdots \\
r_{m 1} & r_{m 2} & \cdots & r_{m n}
\end{array}\right]=\left(\begin{array}{llll}
b_{1} & b_{2} & \cdots & b_{i}
\end{array}\right)
$$

5. According to the Principle of Maximum Membership to Determine the Water Quality Grade.

\subsection{Fuzzy Comprehensive Evaluation Results of Study Area}

According to the above related principles to evaluate the water quality of the study area. Steps are as follows:

1. Select Evaluation Indicators

The selection of $\mathrm{Fe}, \mathrm{Mn}, \mathrm{Cu}, \mathrm{Zn}$, Chloride, Sulfate, Total dissolved solids, Total hardness $\left(\mathrm{CaCO}_{3}\right)$, Volatile phenols (phenol), $\mathrm{Ar}, \mathrm{Cd}, \mathrm{Cr}^{6+}, \mathrm{Pb}, \mathrm{Hg}$, Cyanide and nitrate $(\mathrm{N})$, a total of 16 index. 
2. Determine the Water Quality Criteria

According to the groundwater quality standard, the quality of groundwater is classified into five categories, as shown in table 2 .

Table 2. Sixteen groundwater quality classification indicators

\begin{tabular}{l|l|l|l|l|l}
\hline name & average value & $\max$ & $\min$ & variance & Skewness \\
\hline $\mathrm{pH}$ & 7.68125 & 6.97 & 8.63 & 0.416224 & -0.07243 \\
\hline $\mathrm{Al}$ & 0 & 0 & 0 & 0 & 0 \\
\hline $\mathrm{Fe}$ & 0.0590625 & 0 & 0.35 & 0.075181 & 1.954998 \\
\hline $\mathrm{Mn}$ & 0.0009375 & 0 & 0.01 & 0.002915 & 2.926498 \\
\hline $\mathrm{Cu}$ & 0 & 0 & 0 & 0 & 0 \\
\hline $\mathrm{Zn}$ & 0.0075 & 0 & 0.08 & 0.016583 & 3.269787 \\
\hline Chloride & 65.1453125 & 9.08 & 323.16 & 57.4284 & 2.971266 \\
\hline Sulfate & 100.5184375 & 17.05 & 276.41 & 47.11266 & 1.53416 \\
\hline Total dissolved solids & 640.684375 & 239 & 1779.9 & 263.6166 & 2.525931 \\
\hline Total hardness $\left(\mathrm{CaCO}{ }_{3}\right)$ & 431.2134375 & 179.94 & 1011.51 & 154.9845 & 1.461533 \\
\hline Oxygen consumption & 0.8440625 & 0.27 & 3.36 & 0.689592 & 3.146694 \\
\hline Volatile phenols & 0 & 0 & 0 & 0 & 0 \\
\hline $\mathrm{Ar}$ & 0.00003125 & 0 & 0.001 & 0.000174 & 5.656854 \\
\hline $\mathrm{Cd}$ & 0 & 0 & 0 & 0 & 0 \\
\hline $\mathrm{Cr}{ }^{6+}$ & 0.0054375 & 0 & 0.031 & 0.009107 & 1.810233 \\
\hline $\mathrm{Pb}$ & 0.000115625 & 0 & 0.0037 & 0.000644 & 5.656854 \\
\hline $\mathrm{Hg}$ & 0.0000875 & 0 & 0.0015 & 0.00034 & 3.830122 \\
\hline $\mathrm{Se}$ & 0.000690625 & 0 & 0.0055 & 0.001147 & 2.669964 \\
\hline $\mathrm{Cyanide}$ & 0.00075 & 0 & 0.002 & 0.000968 & 0.542149 \\
\hline $\mathrm{Fluoride}$ & 0.3921875 & 0.18 & 0.83 & 0.134088 & 0.993362 \\
\hline $\mathrm{Nitrate}(\mathrm{N})$ & 19.211875 & 1.03 & 164.91 & 27.31999 & 4.928819 \\
\hline
\end{tabular}
unit:mg/L

\section{Compute Fuzzy Matrix R}

According to formula (1), (2) and (3) calculate the degree of membership of each indicator to the water quality grade, each indicator is calculated to have five levels of membership, and the 16 selected indicators can get 16 sets of numerical value. Taking JYY101 water sample as an example, the fuzzy matrix $\mathrm{R}$ is:

$$
R^{T}=\left[\begin{array}{cccccccccccccccc}
1 & 1 & 1 & 1 & 1 & 1 & 0.34 & 0.577 & 1 & 1 & 1 & 1 & 1 & 1 & 0.889 & 0 \\
0 & 0 & 0 & 0 & 0 & 0 & 0.66 & 0.423 & 0 & 0 & 0 & 0 & 0 & 0 & 0.111 & 0.746 \\
0 & 0 & 0 & 0 & 0 & 0 & 0 & 0 & 0 & 0 & 0 & 0 & 0 & 0 & 0 & 0.254 \\
0 & 0 & 0 & 0 & 0 & 0 & 0 & 0 & 0 & 0 & 0 & 0 & 0 & 0 & 0 & 0 \\
0 & 0 & 0 & 0 & 0 & 0 & 0 & 0 & 0 & 0 & 0 & 0 & 0 & 0 & 0 & 0
\end{array}\right]^{T}
$$

4. Establish the Weight Fuzzy Matrix A

According to formula (8), the weight $\mathrm{W}$ of the 16 indexes is calculated to form a $1 \times 16$ matrix, and the matrix is normalized to obtain a modified weight fuzzy matrix A. Taking JYY101 as an example, the result of weight calculation is:

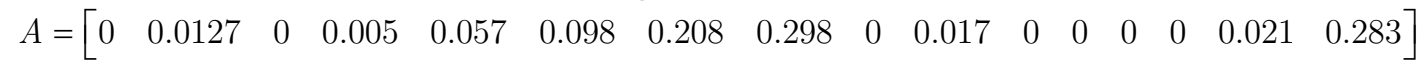

5. Calculation of Membership Degree and Classification of Water Quality

According to formula (7), the above two fuzzy matrix is combined to obtain the membership degree matrix B. For example, JYY101 membership matrix $B=\{0.451258$ $0.476890 .07185100\}$, according to the principle of maximum membership to determine the 
water quality level, of which 0.47689 is the maximum value of five values, in the class II water quality. Therefore, the comprehensive water quality of the monitoring well is determined as category II. According to the above methods, the water quality grades of the other 31 wells in the study area are obtained. The results are shown in table 3.

Table 3. Water quality calculation result of fuzzy comprehensive evaluation method

\begin{tabular}{|c|c|c|c|c|c|c|}
\hline name & $\mathrm{I}$ & II & III & IV & $\mathrm{V}$ & result \\
\hline JYY101 & 0.451258 & 0.47689 & 0.071851 & 0 & 0 & II \\
\hline JYY102 & 0.688795 & 0.311205 & 0 & 0 & 0 & $\mathrm{I}$ \\
\hline JYY103 & 0.194543 & 0.580095 & 0.225363 & 0 & 0 & II \\
\hline JYY105 & 0.167778 & 0.40579 & 0.426433 & 0 & 0 & III \\
\hline JWY115 & 0.120315 & 0.097462 & 0.444693 & 0.135222 & 0.285599 & III \\
\hline JWY119 & 0.164033 & 0.584151 & 0.251816 & 0 & 0 & II \\
\hline JWY121 & 0.062242 & 0.266819 & 0.407208 & 0.263731 & 0 & III \\
\hline JWY123 & 0.272389 & 0.585482 & 0.142129 & 0 & 0 & $\mathrm{II}$ \\
\hline JWY124 & 0.125919 & 0.200056 & 0.274292 & 0.399733 & 0 & IV \\
\hline JWY125 & 0.144404 & 0.292399 & 0.335654 & 0.227544 & 0 & III \\
\hline JWY126 & 0.113148 & 0.255959 & 0.417122 & 0.213987 & 0 & III \\
\hline JYY115 & 0.353654 & 0.56858 & 0.077766 & 0 & 0 & II \\
\hline JYY116 & 0.193292 & 0.386475 & 0.420233 & 0 & 0 & III \\
\hline JYY117 & 0.102765 & 0.336839 & 0.194492 & 0 & 0.365905 & $\mathrm{~V}$ \\
\hline JYY118 & 0.286278 & 0.029097 & 0 & 0 & 0.684625 & $\mathrm{~V}$ \\
\hline JWY130 & 0.62808 & 0.37192 & 0 & 0 & 0 & $\mathrm{I}$ \\
\hline JWY131 & 0.062255 & 0.405553 & 0.284734 & 0.247458 & 0 & II \\
\hline JWY132 & 0.086 & 0.42904 & 0.231869 & 0.253092 & 0 & II \\
\hline JWY133 & 0.017488 & 0.032661 & 0.060033 & 0.139098 & 0.750721 & $\mathrm{~V}$ \\
\hline JWY134 & 0.136372 & 0.398837 & 0.464792 & 0 & 0 & III \\
\hline JWY140 & 0.093397 & 0.33349 & 0.263152 & 0 & 0.309961 & II \\
\hline Luonan1\# & 0.232207 & 0.662872 & 0.104921 & 0 & 0 & $\mathrm{II}$ \\
\hline Zhangzhuang7\# & 0.194192 & 0.650897 & 0.154911 & 0 & 0 & II \\
\hline Linjian4\# & 0.120881 & 0.178564 & 0.406049 & 0.294506 & 0 & III \\
\hline Wangfuzhuang9\# & 0.067561 & 0.214472 & 0.407844 & 0.010104 & 0.300019 & III \\
\hline Xiachi1\# & 0.185629 & 0.607841 & 0.20653 & 0 & 0 & II \\
\hline Lilou13\# & 0.130415 & 0.164518 & 0.590886 & 0.11418 & 0 & III \\
\hline Dongjiao1\# & 0.120006 & 0.166261 & 0.285631 & 0.428102 & 0 & IV \\
\hline Roulian factory $4 \#$ & 0.123157 & 0.144897 & 0.280692 & 0.132684 & 0.31857 & $\mathrm{~V}$ \\
\hline Tuo factory $6 \#$ & 0.186057 & 0.305634 & 0.47421 & 0.034099 & 0 & III \\
\hline Foreign Language Institute1\# & 0.163156 & 0.215524 & 0.566154 & 0.055165 & 0 & III \\
\hline Steel mill living quarters & 0.147715 & 0.498155 & 0.35413 & 0 & 0 & II \\
\hline
\end{tabular}

\subsection{Groundwater quality Evaluation Based on Comprehensive Index Method}

According to the "Groundwater environmental quality standard" (GB/T14848-93 [S]), the comprehensive evaluation of groundwater quality by annotated scoring methods should be performed as follows. Firstly, evaluate the individual component to determine the quality category. Secondly, according to the table 4 determine the individual component evaluation score $F_{i}$, and then according to equation (9) calculate the comprehensive evaluation score F. Finally, according to the F value classify groundwater quality level.

Table 4. Evaluation score table for single fator 


\begin{tabular}{c|c|c|c|c|c}
\hline sort & I & II & III & IV & V \\
\hline$F_{\mathrm{i}}$ & 0 & 1 & 3 & 6 & 10 \\
\hline
\end{tabular}

$$
\begin{gathered}
\bar{F}=\frac{1}{\mathrm{n}} \sum_{i=1}^{n} F_{i} \\
F=\sqrt{\frac{F_{\text {max }}^{2}+\bar{F}^{2}}{2}}
\end{gathered}
$$

where, $\bar{F}$ is the average value of each individual component score $\mathrm{F}_{\mathrm{i}}$;

$F_{\max }$ is the maximum value of the individual component evaluation score $F_{i}$;

$n$ is the index number.

Table 5. Comprehensive classification scoring table for groundwater quality

\begin{tabular}{cccccc}
\hline sort & excellent & good & preferably & poor & range \\
\hline $\mathrm{F}$ & $\mathrm{F}<0.8$ & $0.8 \leq \mathrm{F}<2.5$ & $2.5 \leq \mathrm{F}<4.25$ & $4.25 \leq \mathrm{F}<7.20$ & $\mathrm{~F} \geq 7.20$ \\
\hline
\end{tabular}

According to the above methods the $\mathrm{F}$ value can be calculated, and according to Table 5, the groundwater quality level in the study area is shown in Table 6.

Table 6. Calculation results table of comprehensive index method

\begin{tabular}{l|c|c|l|c|c}
\hline name & F & sort & name & F & sort \\
\hline JYY101 & 2.132 & II & JWY131 & 4.290 & IV \\
\hline JYY102 & 0.711 & I & JWY132 & 4.276 & IV \\
\hline JYY103 & 2.157 & II & JWY133 & 7.191 & IV \\
\hline JYY105 & 2.163 & II & JWY134 & 2.187 & II \\
\hline JWY115 & 7.131 & IV & JWY140 & 7.110 & IV \\
\hline JWY119 & 2.157 & II & Zhangzhuang7\# & 2.145 & II \\
\hline JWY121 & 4.271 & IV & Linjian4\# & 2.145 & II \\
\hline JWY123 & 2.145 & II & Wangfuzhuang9\# & 4.290 & IV \\
\hline JWY124 & 4.295 & IV & Xiachi1\# & 4.301 & IV \\
\hline JWY125 & 4.271 & IV & Lilou13\# & 2.157 & II \\
\hline JWY126 & 4.301 & IV & Dongjiao1\# & 4.285 & IV \\
\hline JYY115 & 2.129 & II & Roulian factory 4\# & 4.290 & IV \\
\hline JYY116 & 2.151 & II & Tuo factory 6\# & 4.290 & IV \\
\hline JYY117 & 7.114 & IV & Foreign Language Institute1\# & 4.290 & IV \\
\hline JYY118 & 7.082 & IV & Steel mill living quarters & 4.290 & IV \\
\hline JWY130 & 4.260 & IV & Zhangzhuang7\# & 2.157 & II \\
\hline
\end{tabular}

\subsection{Evaluation Result Analysis}

A comprehensive evaluation of Luoyang groundwater was conducted by resorting to fuzzy mathematics. Water sample I, sample II, sample III, sample IV, sample V accounted for $6.25 \%, 37.5 \%, 37.5 \%, 6.25,12.5 \%$ of the total. The traditional GB method evaluated the quality of groundwater in the study area, water sample I, sample II, sample IV account for $3.12 \%, 37.5 \%, 59.38 \%$ respectively.

It can be seen that the water quality comprehensive index evaluation method highlights the largest pollution factor, and the index classification is based on the binary logic, thus cannot describe the continuity of environmental quality, and cannot objectively reflect the influence of the index value near the water quality grade limit on the water quality evaluation and classification. So the result of evaluation is extreme, and it is not suitable for the evaluation of groundwater quality in the study area. Fuzzy 
comprehensive evaluation using membership degree to evaluate groundwater quality, considering the weight of each factor, can reflect how close the actual concentration of boundary water quality index of water quality; make the evaluation more comprehensive and reasonable.

\section{$5 \quad$ Mechanism Analysis of Groundwater Pollution in Study Area}

The main groundwater pollutants in the study area are total hardness and nitrate. The total hardness of more than $450 \mathrm{mg} / \mathrm{L}$ is classified as extremely hard water, fail to reach the water quality standard is exceeded. The total hardness of the study area is mainly concentrated in the third class. Total hardness excessive monitoring wells for 16, the over-standard rate of the total number was $50 \%$. Nitrate excessive monitoring wells for 10, the over-standard rate of the total number was $31.25 \%$. According to the distribution of groundwater quality in the study area (Fig. 2), industrial waste water discharge is due to Pangcun Town Industrial Zone, Baima Temple Huoquan Industrial Zone, Hongshan Township Industrial Zone, Li Village, Nanzhai Industrial Zone and other local factories gathered. Excessive discharge of industrial waste water and domestic sewage is the main cause of groundwater polluttion.

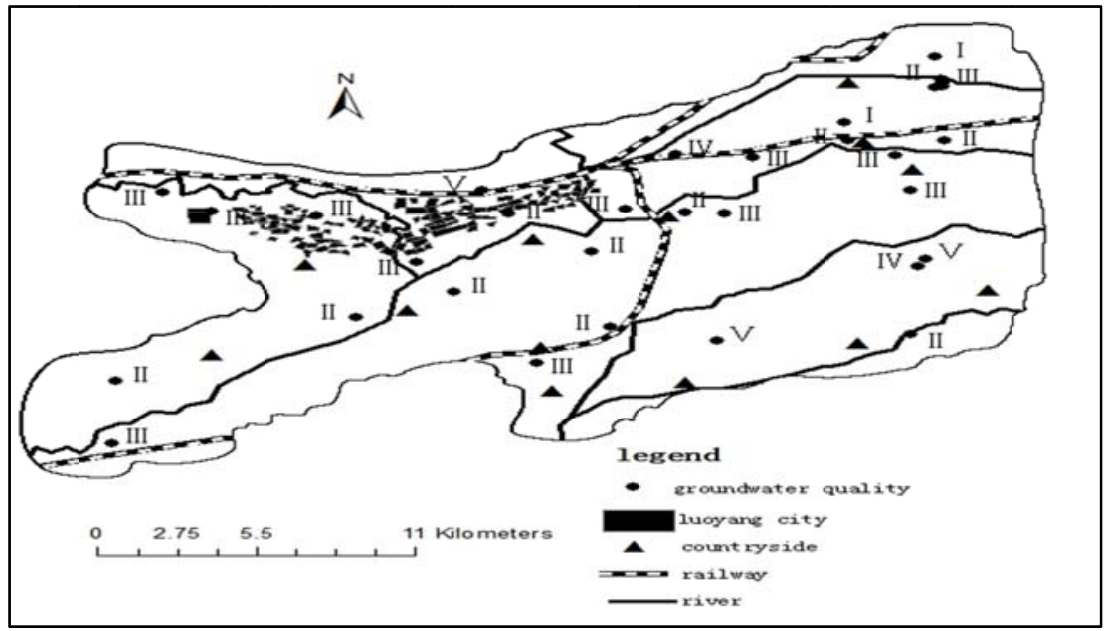

Figure 2. Distribution of groundwater quality in the study area

\section{Conclusion}

The following conclusions can be obtained through the evaluation of the groundwater quality of 32 water samples in Luoyang city in 2012:

1. A comprehensive evaluation of Luoyang groundwater was conducted by resorting to fuzzy mathematics. Water sample I, sample II, sample III, sample IV, sample V accounted for $6.25 \%, 37.5 \%, 37.5 \%, 6.25,12.5 \%$ of the total. The groundwater quality was largely at a moderate state;

2. The pollution degree of water quality belongs to the fuzzy concept. Compared with the traditional groundwater comprehensive index method, the fuzzy mathematics method is more in line with the water quality of the study area, and it is a better method for groundwater quality evaluation;

3. The spatial distribution of groundwater quality is obviously more serious in industrial parks and residential areas;

4. The main excessive components of groundwater in the region are the total hardness and nitrate. In order to improve the status of groundwater and reasonable scientific planning of groundwater extraction, it is necessary to strictly control the industrial wastewater and domestic sewage discharge. 
Acknowledgment. This work was supported by National Science and Technology Major Project of Ministry of Science and Technology of China (No. 2016ZX050404-001).

\section{References}

1. Guoming Wen, Xiang Li, Hongxia Ma, et al. Research on water quality safety of drinking water source in luoyang [J]. China Safety Science Journal, 2007, 17(3):15-20.

2. Liu G D, Wu W L, Zhang J. Regional differentiation of non-point source pollution of agriculture-derived nitrate nitrogen in groundwater in northern China[J]. Agriculture Ecosystems \& Environment, 2005, 107(2-3):211-220.

3. Xianguo Wang, Tao Peng. The evolution analysis of Shallow pore groundwater chemical environment of Luoyang city[J]. Yellow River, 2009, 31(4):58-60.

4. Gang Qiao. Dynamic characteristics of the groundwater environment in Luoyang city[J]. Groundwater, 2014(3):74-75.

5. Zhikai Wang, Kefeng Zhang, Lei Liu. Optimization of single factor index method in groundwater contamination assessment[J]. Environment Engineering.2016(S1):810-812

6. Yan Yang, Weiwei Wei, Dinglong Li, et al. Study on groundwater pollution in Changzhou City [J]. Groundwater, 2012(1):77-79.

7. Ming Zhang, Dongdong Gao, Chengjiang He, et al. Environment quality evaluation of Deyang plain groundwater based on fuzzy mathematics[J]. Environment Engineering, 2016, 34(4):151-155.

8. Kai G, Wei J. TS Fuzzy Water Quality of Hanjiang River in Hanzhong Section Based on Neural Network Evaluation[J]. Microcomputer Applications, 2016, 2: 015.

9. Guofang M, Shu S, Lan W. Analysis on Groundwater Drinking Water Quality in Jiamusi City[J]. Environmental Science and Management, 2015, 7: 040.

10.Gang Kong, Quanjiu Wang, Qiang Huang. Groundwater quality evaluation of Changping piedmont plain in Beijing Province based on BP neural network [J]. Transactions of the Chinese Society of Agricultural Engineering, 2017, 33(z1):150-156.

11. Chunsheng Fang, He Meng, Yushu Shan, Fuzzy comprehensive evaluation of groundwater quality based on GIS of Jinlin province[J]. Journal of Jilin University(Earth Science Edition), 2011(s1):293-297.

12.Li Li. Analysis of microbial contamination of groundwater in Luoyang [J]. Groundwater, 2012(3):102-103.

13.Rong Ma, Jiansheng Shi. Assessing groundwater pollution using fuzzy factor analysis method: a case study of Luoyang city in Henan province[J]. Acta Geoscient Sinica, 2011, 32(5):611-622.

14.Youqing Guo, Shanfeng Qiang, Zongwei Wu, et al. Present situation of water resources and analysis and prediction of groundwater dynamics in Luoyang [J]. Yellow River, 2006, 28(7):63-64.

15.Vadiati M, Asghari-Moghaddam A, Nakhaei M, et al. A fuzzy-logic based decision-making approach for identification of groundwater quality based on groundwater quality indices[J]. Journal of Environmental Management, 2016, 184:255-270. 